\title{
Some new theorems of expanding mappings without continuity in cone metric spaces
}

Yan $\operatorname{Han}^{1}$ and Shaoyuan $\mathrm{Xu}^{2^{*}}$

${ }^{*}$ Correspondence:

xushaoyuan@126.com

${ }^{2}$ School of Mathematics and

Statistics, Hubei Normal University,

Huangshi, 435002, P.R. China

Full list of author information is

available at the end of the article

\begin{abstract}
In this paper, fixed point theorems for one mapping and common fixed point theorems for two mappings satisfying generalized expansive conditions are obtained. The mappings are not necessarily continuous and the cone is not normal. These results improve and generalize several well-known comparable results in (Aage and Salunke, in Acta Mathematica Sinica, English Series 27(6):1101-1106, 2011). Moreover, examples are given to support our new results.
\end{abstract}

MSC: $54 \mathrm{H} 25 ; 47 \mathrm{H} 10$

Keywords: cone metric space; expanding mapping; common fixed point

\section{Introduction and preliminaries}

Recently, Huang and Zhang [1] introduced the concept of a cone metric space as a generalization of a metric space. They proved the properties of sequences in cone metric spaces and obtained various fixed point theorems for contractive mappings. Afterwords, Abbas and Jungck [2] established the common fixed points for two mappings without exploiting the notion of continuity. Since then, common fixed point theorems in cone metric spaces have been proved for mappings satisfying different contractive conditions by many authors (see [3-8]). But there are few results about expanding mappings. Chintaman and Jagannath [9] introduced several meaningful fixed point theorems for one expanding mapping. However, the mapping depended strongly on continuity. In this paper, we delete the continuity of the mappings and obtain some fixed point theorems for one expanding mapping and introduce common fixed point theorems for two expanding mappings, which satisfy generalized expansive conditions in nonnormal cone metric spaces. These results improve and generalize some important known results in $[9,10]$.

We recall some definitions of cone metric spaces and some of their properties [1]. Let $E$ be a real Banach space and $P$ be a subset of $E$. $\theta$ denotes the zero element of $E$ and int $P$ denotes the interior of $P$. The subset $P$ is called a cone if and only if:

(i) $P$ is closed, nonempty and $P \neq\{\theta\}$,

(ii) $a, b \in \mathbb{R}, a, b \geq 0, x, y \in P \Rightarrow a x+b y \in P$,

(iii) $x \in P$ and $-x \in P \Rightarrow x=\theta$.

Given a cone $P \subset E$, we define a partial ordering $\leq$ with respect to $P$ by $x \leq y$ if and only if $y-x \in P$. We will write $x<y$ if $x \leq y$ and $x \neq y$, while $x \ll y$ will stand for $y-x \in \operatorname{int} P$. A cone $P$ is called normal if there is a number $K>0$ such that for all $x, y \in P$,

$$
\theta \leq x \leq y \text { implies } \quad\|x\| \leq K\|y\| .
$$

(c) $2013 \mathrm{Han}$ and $\mathrm{Xu}$; licensee Springer. This is an Open Access article distributed under the terms of the Creative Commons Attribution License (http://creativecommons.org/licenses/by/2.0), which permits unrestricted use, distribution, and reproduction in any medium, provided the original work is properly cited. 
The least positive number satisfying the above inequality is called the normal constant of $P$.

Definition 1.1 ([1]) Let $X$ be a nonempty set. Suppose that the mapping $d: X \times X \rightarrow E$ satisfies the following:

(d1) $\theta \leq d(x, y)$ for all $x, y \in X$ and $d(x, y)=\theta$ if and only if $x=y$;

(d2) $d(x, y)=d(y, x)$ for all $x, y \in X$;

(d3) $d(x, y) \leq d(x, z)+d(z, y)$ for all $x, y, z \in X$.

Then $d$ is called a cone metric on $X$ and $(X, d)$ is called a cone metric space. It is clear that the cone metric space is more general than a metric space.

Definition $1.2([1])$ Let $(X, d)$ be a cone metric space. Then we say that $\left\{x_{n}\right\}$ is

(i) a Cauchy sequence if for every $c \in E$ with $c \gg \theta$, there is $N$ such that for all $n, m>N, d\left(x_{n}, x_{m}\right) \ll c$

(ii) a convergent sequence if for every $c \in E$ with $c \gg \theta$, there is $N$ such that for all $m>N, d\left(x_{m}, x\right) \ll c$ for some fixed $x$ in $X$.

A cone metric space $X$ is said to be complete if every Cauchy sequence in $X$ is convergent in $X$.

Lemma 1.3 ([11]) The limit of a convergent sequence in a cone metric space is unique.

\section{Main results}

In this section, we prove some fixed point theorems for expanding mappings without continuity in the following theorems.

Theorem 2.1 Let $(X, d)$ be a complete cone metric space. Suppose the mapping $f: X \rightarrow X$ is onto and satisfies

$$
d(f x, f y) \geq a_{1} d(x, y)+a_{2} d(x, f x)+a_{3} d(y, f y)+a_{4} d(x, f y)+a_{5} d(y, f x)
$$

for all $x, y \in X$, where $a_{i}(i=1,2,3,4,5)$ satisfies $a_{1}+a_{2}+a_{3}>1$ and $a_{3} \leq 1+a_{4}$. Then $f$ has a fixed point.

Proof Since $f$ is an onto mapping, for each $x_{0} \in X$, there exists $f x_{1}=x_{0}$. Continuing this process, we can define $\left\{x_{n}\right\}$ by $x_{n}=f x_{n+1}, n=0,1,2, \ldots$ Without loss of generality, we suppose that $x_{n-1} \neq x_{n}$ for all $n \geq 1$. According to (2.1), we have

$$
\begin{aligned}
d\left(x_{n}, x_{n-1}\right)= & d\left(f x_{n+1}, f x_{n}\right) \\
\geq & a_{1} d\left(x_{n+1}, x_{n}\right)+a_{2} d\left(x_{n+1}, f x_{n+1}\right)+a_{3} d\left(x_{n}, f x_{n}\right) \\
& +a_{4} d\left(x_{n+1}, f x_{n}\right)+a_{5} d\left(x_{n}, f x_{n+1}\right) \\
= & a_{1} d\left(x_{n+1}, x_{n}\right)+a_{2} d\left(x_{n+1}, x_{n}\right)+a_{3} d\left(x_{n}, x_{n-1}\right)+a_{4} d\left(x_{n+1}, x_{n-1}\right)+a_{5} d\left(x_{n}, x_{n}\right) .
\end{aligned}
$$

By $d\left(x_{n+1}, x_{n-1}\right) \geq d\left(x_{n+1}, x_{n}\right)-d\left(x_{n-1}, x_{n}\right)$, the above inequality implies that

$$
d\left(x_{n+1}, x_{n}\right) \leq \frac{1-a_{3}+a_{4}}{a_{1}+a_{2}+a_{4}} d\left(x_{n}, x_{n-1}\right) .
$$


Let $h=\frac{1-a_{3}+a_{4}}{a_{1}+a_{2}+a_{4}}$. By $a_{3} \leq 1+a_{4}$ and $a_{1}+a_{2}+a_{3}>1$, we know $a_{1}+a_{2}+a_{4}>1-a_{3}+a_{4} \geq 0$ and $h \in[0,1)$. Hence, we get

$$
d\left(x_{n+1}, x_{n}\right) \leq h d\left(x_{n}, x_{n-1}\right) .
$$

So, by the triangle inequality, for any $n>m$, we see

$$
\begin{aligned}
d\left(x_{n}, x_{m}\right) & \leq d\left(x_{n}, x_{n-1}\right)+d\left(x_{n-1}, x_{n-2}\right)+\cdots+d\left(x_{m+1}, x_{m}\right) \\
& \leq\left(h^{n-1}+h^{n-2}+\cdots+h^{m}\right) d\left(x_{1}, x_{0}\right) \\
& \leq \frac{h^{m}}{1-h} d\left(x_{1}, x_{0}\right) .
\end{aligned}
$$

Thus, as $h \in[0,1)$, we can choose a natural number $N_{0}$ such that $\frac{h^{m}}{1-h} d\left(x_{1}, x_{0}\right) \ll c$ for each $c \gg \theta$ and $m>N_{0}$. Hence, we see

$$
d\left(x_{n}, x_{m}\right) \ll c \text { for all } n>m>N_{0} .
$$

Therefore, $\left\{x_{n}\right\}$ is a Cauchy sequence in $(X, d)$.

Since $X$ is complete, there exists $q \in X$ such that $f x_{n+1}=x_{n} \rightarrow q$ as $n \rightarrow \infty$. Consequently, we can find a $p \in X$ such that $f p=q$. Now, we show that $p=q$. Substituting $x=p, y=x_{n+1}$ in (2.1), we get

$$
\begin{aligned}
d\left(q, x_{n}\right) & =d\left(f p, f x_{n+1}\right) \\
& \geq a_{1} d\left(p, x_{n+1}\right)+a_{2} d(p, f p)+a_{3} d\left(x_{n+1}, f x_{n+1}\right)+a_{4} d\left(p, f x_{n+1}\right)+a_{5} d\left(x_{n+1}, f p\right) .
\end{aligned}
$$

For the second and fourth term on the right-hand side, we have $d(p, q) \geq d\left(p, x_{n+1}\right)-$ $d\left(q, x_{n+1}\right)$ and $d\left(p, x_{n}\right) \geq d\left(p, x_{n+1}\right)-d\left(x_{n}, x_{n+1}\right)$. For the left-hand side, $d\left(q, x_{n}\right) \leq d\left(q, x_{n+1}\right)+$ $d\left(x_{n+1}, x_{n}\right)$. It follows that

$$
\left(a_{1}+a_{2}+a_{4}\right) d\left(p, x_{n+1}\right) \leq\left(1+a_{2}-a_{5}\right) d\left(q, x_{n+1}\right)+\left(1-a_{3}+a_{4}\right) d\left(x_{n+1}, x_{n}\right) .
$$

Now, we have

$$
\begin{aligned}
d\left(p, x_{n+1}\right) & \leq \frac{1+a_{2}-a_{5}}{a_{1}+a_{2}+a_{4}} d\left(q, x_{n+1}\right)+\frac{1-a_{3}+a_{4}}{a_{1}+a_{2}+a_{4}} d\left(x_{n+1}, x_{n}\right) \\
& \leq \frac{1+a_{2}-a_{5}}{a_{1}+a_{2}+a_{4}} d\left(q, x_{n+1}\right)+d\left(x_{n+1}, x_{n}\right) .
\end{aligned}
$$

If $1+a_{2}-a_{5}>0$ for each $c \gg \theta$, we can choose a natural number $N_{1}$ such that $d\left(x_{n+1}, x_{n}\right) \ll \frac{c}{2}$ and $d\left(q, x_{n+1}\right) \ll \frac{\left(a_{1}+a_{2}+a_{4}\right) c}{2\left(1+a_{2}-a_{5}\right)}$ for $n \geq N_{1}$. Thus, we obtain

$$
\begin{aligned}
d\left(p, x_{n+1}\right) & \ll \frac{c}{2}+\frac{c}{2}=c . \\
\text { If } 1+a_{2}-a_{5} & \leq 0 \text { for } n \geq N_{1}, \\
d\left(p, x_{n+1}\right) & \leq d\left(x_{n+1}, x_{n}\right) \ll \frac{c}{2} \ll c .
\end{aligned}
$$

Therefore, $x_{n+1} \rightarrow p$. From Lemma 1.3, we see $p=q$. The conclusion is true. 
Taking some particular value of $a_{i}(i=1,2,3,4,5)$ in Theorem 2.1, we obtain several new results in the following.

Corollary 2.2 Let $(X, d)$ be a complete cone metric space. Suppose the mapping $f: X \rightarrow X$ is onto and satisfies

$$
d(f x, f y) \geq k d(x, y)+l d(x, f x)+p d(y, f y)
$$

for all $x, y \in X$, where $p \leq 1$ and $k+l+p>1$. Then $f$ has a fixed point.

Corollary 2.3 Let $(X, d)$ be a complete cone metric space. Suppose the mapping $f: X \rightarrow X$ is onto and satisfies

$$
d(f x, f y) \geq k d(x, y)+l d(f x, y)
$$

for all $x, y \in X$, where $k, l$ are constants and $k>1$. Then $f$ has a fixed point.

Remark 2.4 Obviously, in our theorem and its corollaries above, we delete the continuity of the mappings which is essential in the results of [9]. Moreover, in Corollary 2.2 we delete $k \geq-1, l>1$, which is essential in Theorem 2.6 in [9]. In Corollary 2.3 we delete $l \geq 0$, which is essential in Theorem 2.5 in [9]. Theorem 2.3 in [9] is a special case of Theorem 2.1 with $a_{1}=a_{4}=a_{5}=0, a_{2}=a_{3}=K$, and $f$ is continuous.

Now, we introduce some common fixed point theorems for two expanding mappings which satisfy generalized expansive conditions without continuity of the mappings.

Theorem 2.5 Let $(X, d)$ be a complete cone metric space. Suppose mappings $f, g: X \rightarrow X$ are onto and satisfy

$$
d(f x, g y) \geq a_{1} d(x, y)+a_{2} d(x, f x)+a_{3} d(y, g y)+a_{4} d(x, g y)+a_{5} d(y, f x)
$$

for all $x, y \in X$, where $a_{i}(i=1,2,3,4,5)$ satisfies $a_{1}+a_{2}+a_{3}>1$ and $a_{2} \leq 1+a_{5}, a_{3} \leq 1+a_{4}$. Then $f$ and $g$ have a common fixed point.

Proof Suppose $x_{0}$ is an arbitrary point in $X$. Since $f, g$ are onto, there exist $x_{1}, x_{2} \in X$ such that $x_{0}=g x_{1}, x_{1}=f x_{2}$. Continuing this process, we can define $\left\{x_{n}\right\}$ by $x_{2 n}=g x_{2 n+1}, x_{2 n+1}=$ $f x_{2 n+2}, n=0,1,2, \ldots$ By $(2.2)$, we have

$$
\begin{aligned}
d\left(x_{2 n+1}, x_{2 n}\right)= & d\left(f x_{2 n+2}, g x_{2 n+1}\right) \\
\geq & a_{1} d\left(x_{2 n+2}, x_{2 n+1}\right)+a_{2} d\left(x_{2 n+2}, f x_{2 n+2}\right)+a_{3} d\left(x_{2 n+1}, g x_{2 n+1}\right) \\
& +a_{4} d\left(x_{2 n+2}, g x_{2 n+1}\right)+a_{5} d\left(x_{2 n+1}, f x_{2 n+2}\right) \\
= & a_{1} d\left(x_{2 n+2}, x_{2 n+1}\right)+a_{2} d\left(x_{2 n+2}, x_{2 n+1}\right)+a_{3} d\left(x_{2 n+1}, x_{2 n}\right) \\
& +a_{4} d\left(x_{2 n+2}, x_{2 n}\right)+a_{5} d\left(x_{2 n+1}, x_{2 n+1}\right) .
\end{aligned}
$$

Since $d\left(x_{2 n+2}, x_{2 n}\right) \geq d\left(x_{2 n+2}, x_{2 n+1}\right)-d\left(x_{2 n}, x_{2 n+1}\right)$, the above inequality implies that

$$
\left(1-a_{3}+a_{4}\right) d\left(x_{2 n}, x_{2 n+1}\right) \geq\left(a_{1}+a_{2}+a_{4}\right) d\left(x_{2 n+1}, x_{2 n+2}\right) .
$$


Similarly, it can be shown that

$$
\begin{aligned}
d\left(x_{2 n-1}, x_{2 n}\right)= & d\left(f x_{2 n}, g x_{2 n+1}\right) \\
\geq & a_{1} d\left(x_{2 n}, x_{2 n+1}\right)+a_{2} d\left(x_{2 n}, f x_{2 n}\right)+a_{3} d\left(x_{2 n+1}, g x_{2 n+1}\right) \\
& +a_{4} d\left(x_{2 n}, g x_{2 n+1}\right)+a_{5} d\left(x_{2 n+1}, f x_{2 n}\right) \\
= & a_{1} d\left(x_{2 n}, x_{2 n+1}\right)+a_{2} d\left(x_{2 n}, x_{2 n-1}\right)+a_{3} d\left(x_{2 n+1}, x_{2 n}\right) \\
& +a_{4} d\left(x_{2 n}, x_{2 n}\right)+a_{5} d\left(x_{2 n+1}, x_{2 n-1}\right),
\end{aligned}
$$

which also implies that

$$
\left(1-a_{2}+a_{5}\right) d\left(x_{2 n-1}, x_{2 n}\right) \geq\left(a_{1}+a_{3}+a_{5}\right) d\left(x_{2 n}, x_{2 n+1}\right) .
$$

Let $M=\frac{1-a_{3}+a_{4}}{a_{1}+a_{2}+a_{4}}, N=\frac{1-a_{2}+a_{5}}{a_{1}+a_{3}+a_{5}}$. From $a_{1}+a_{2}+a_{3}>1$ and $a_{2} \leq 1+a_{5}, a_{3} \leq 1+a_{4}$, we see $a_{1}+a_{2}+a_{4}>1-a_{3}+a_{4} \geq 0$ and $a_{1}+a_{3}+a_{5}>1-a_{2}+a_{5} \geq 0$. Thus, $h=M N \in[0,1)$. Now, by induction we have

$$
\begin{aligned}
d\left(x_{2 n+2}, x_{2 n+1}\right) & \leq M d\left(x_{2 n+1}, x_{2 n}\right) \leq M N d\left(x_{2 n}, x_{2 n-1}\right) \\
& \leq M^{2} N d\left(x_{2 n-1}, x_{2 n-2}\right) \leq \cdots \leq M h^{n} d\left(x_{1}, x_{0}\right)
\end{aligned}
$$

and

$$
d\left(x_{2 n+1}, x_{2 n}\right) \leq N d\left(x_{2 n}, x_{2 n-1}\right) \leq \cdots \leq h^{n} d\left(x_{1}, x_{0}\right) .
$$

Hence, for any $n>m$, we deduce

$$
\begin{aligned}
d\left(x_{2 n+1}, x_{2 m+1}\right) & \leq d\left(x_{2 n+1}, x_{2 n}\right)+d\left(x_{2 n}, x_{2 n-1}\right)+\cdots+d\left(x_{2 m+2}, x_{2 m+1}\right) \\
& \leq\left(\sum_{i=m+1}^{n} h^{i}+M \sum_{i=m}^{n-1} h^{i}\right) d\left(x_{1}, x_{0}\right) \\
& \leq\left(\frac{h^{m+1}}{1-h}+\frac{M h^{m}}{1-h}\right) d\left(x_{1}, x_{0}\right) \\
& =(N+1) \frac{M h^{m}}{1-h} d\left(x_{1}, x_{0}\right) .
\end{aligned}
$$

In an analogous way, we gain

$$
\begin{aligned}
& d\left(x_{2 n}, x_{2 m+1}\right) \leq(N+1) \frac{M h^{m}}{1-h} d\left(x_{1}, x_{0}\right), \\
& d\left(x_{2 n}, x_{2 m}\right) \leq(M+1) \frac{h^{m}}{1-h} d\left(x_{1}, x_{0}\right)
\end{aligned}
$$

and

$$
d\left(x_{2 n+1}, x_{2 m}\right) \leq(M+1) \frac{h^{m}}{1-h} d\left(x_{1}, x_{0}\right)
$$


Thus, for $n>m>0$,

$$
d\left(x_{n}, x_{m}\right) \leq \max \left\{(N+1) \frac{M h^{m}}{1-h},(M+1) \frac{h^{m}}{1-h}\right\} d\left(x_{1}, x_{0}\right)=\lambda_{m} d\left(x_{1}, x_{0}\right),
$$

where $\lambda_{m} \rightarrow 0$ as $m \rightarrow \infty$.

For each $c \gg \theta$, choose $\delta>0$ such that $c-x \in$ int $P$, where $\|x\|<\delta$, i.e., $x \ll c$. For this $\delta$, we can choose a natural number $N_{2}$ such that $\left\|\lambda_{m} d\left(x_{1}, x_{0}\right)\right\|<\delta$ for $m>N_{2}$. Thus, we get

$$
d\left(x_{n}, x_{m}\right) \leq \lambda_{m} d\left(x_{1}, x_{0}\right) \ll c \quad \text { for all } n>m>N_{2} \text {. }
$$

Therefore, $\left\{x_{n}\right\}$ is a Cauchy sequence in $(X, d)$.

As $X$ is complete, there exists $q \in X$ such that $x_{n} \rightarrow q$ as $n \rightarrow \infty$. It is equivalent to $x_{2 n}=g x_{2 n+1} \rightarrow q, x_{2 n+1}=f x_{2 n+2} \rightarrow q$ as $n \rightarrow \infty$. Since $f, g$ are onto, there exist $u, p \in X$ such that $f u=g p=q$. Now, we show that $u=p=q$. By (2.2), we have

$$
\begin{aligned}
d\left(f x_{2 n+2}, g p\right) \geq & a_{1} d\left(x_{2 n+2}, p\right)+a_{2} d\left(x_{2 n+2}, f x_{2 n+2}\right)+a_{3} d(p, g p) \\
& +a_{4} d\left(x_{2 n+2}, g p\right)+a_{5} d\left(p, f x_{2 n+2}\right),
\end{aligned}
$$

that is,

$$
d\left(x_{2 n+1}, q\right) \geq a_{1} d\left(x_{2 n+2}, p\right)+a_{2} d\left(x_{2 n+2}, x_{2 n+1}\right)+a_{3} d(p, q)+a_{4} d\left(x_{2 n+2}, q\right)+a_{5} d\left(p, x_{2 n+1}\right) .
$$

From the fact that $d(p, q) \geq d\left(p, x_{2 n+2}\right)-d\left(q, x_{2 n+2}\right), d\left(p, x_{2 n+1}\right) \geq d\left(p, x_{2 n+2}\right)-d\left(x_{2 n+1}, x_{2 n+2}\right)$ and $d\left(x_{2 n+1}, q\right) \leq d\left(x_{2 n+1}, x_{2 n+2}\right)+d\left(x_{2 n+2}, q\right)$, we get

$$
\left(a_{1}+a_{3}+a_{5}\right) d\left(p, x_{2 n+2}\right) \leq\left(1+a_{3}-a_{4}\right) d\left(x_{2 n+2}, q\right)+\left(1-a_{2}+a_{5}\right) d\left(x_{2 n+1}, x_{2 n+2}\right) .
$$

Now, we have

$$
\begin{aligned}
d\left(p, x_{2 n+2}\right) & \leq \frac{1+a_{3}-a_{4}}{a_{1}+a_{3}+a_{5}} d\left(x_{2 n+2}, q\right)+\frac{1-a_{2}+a_{5}}{a_{1}+a_{3}+a_{5}} d\left(x_{2 n+1}, x_{2 n+2}\right) \\
& \leq \frac{2}{a_{1}+a_{3}+a_{5}} d\left(x_{2 n+2}, q\right)+d\left(x_{2 n+1}, x_{2 n+2}\right) .
\end{aligned}
$$

For each $c \gg \theta$, we can choose a natural number $N_{3}$ such that $d\left(x_{2 n+1}, x_{2 n+2}\right) \ll \frac{c}{2}$ and $d\left(x_{2 n+2}, q\right) \ll \frac{\left(a_{1}+a_{3}+a_{5}\right) c}{4}$ for $n \geq N_{3}$. Hence, we obtain $d\left(p, x_{2 n+2}\right) \ll \frac{c}{2}+\frac{c}{2}=c$, i.e., $x_{2 n+2} \rightarrow p$. By Lemma 1.3, we know $p=q, g q=q$. Similarly, we also have

$$
\begin{aligned}
d\left(f u, g x_{2 n+1}\right) \geq & a_{1} d\left(u, x_{2 n+1}\right)+a_{2} d(u, f u)+a_{3} d\left(x_{2 n+1}, g x_{2 n+1}\right) \\
& +a_{4} d\left(u, g x_{2 n+1}\right)+a_{5} d\left(x_{2 n+1}, f u\right) .
\end{aligned}
$$

As in the previous proof, it is not difficult to get $q=u$, i.e., $f q=q$. Therefore, $f q=g q=q$.

Corollary 2.6 Let $(X, d)$ be a complete cone metric space. Suppose mappings $f, g: X \rightarrow X$ are onto and satisfy

$$
d(f x, g y) \geq \alpha d(x, y)+\beta[d(x, f x)+d(y, g y)]+\gamma[d(x, g y)+d(y, f x)]
$$

for all $x, y \in X$, where $\beta \leq 1+\gamma$ and $\alpha+2 \beta>1$. Then $f$ and $g$ have a common fixed point. 
Corollary 2.7 Let $(X, d)$ be a complete cone metric space. Suppose mappings $f, g: X \rightarrow X$ are onto and satisfy

$$
d(f x, g y) \geq k d(x, y)
$$

for all $x, y \in X$, where $k>1$ is a constant. Then $f$ and $g$ have a unique common fixed point.

Corollary 2.8 Let $(X, d)$ be a complete cone metric space. Suppose the mapping $f: X \rightarrow X$ is onto and satisfies

$$
d\left(f^{p} x, f^{q} y\right) \geq k d(x, y)
$$

for all $x, y \in X$, where $p, q$ are positive integers and $k>1$ is a constant. Then $f$ has a unique fixed point.

Proof Let $f=f^{p}, g=f^{q}$. Since $f$ is an onto mapping, $f=f^{p}, g=f^{q}$ are onto mappings, the conditions of Corollary 2.7 are satisfied.

Remark 2.9 In Corollary 2.8, we obtain Corollary 2.2 in [9] when we take $p=q$.

Now, we present the following examples. In Example 1, we gain a fixed point for one expanding mapping of the situation when Corollary 2.2 can be applied, while the results in [9] cannot. In Example 2, we obtain the common fixed point for two expanding mappings in a cone metric space.

Example 1 Let $X=[1,+\infty), E=C_{\mathbb{R}}^{2}([0,1])$ with $\|x\|=\|x\|_{\infty}+\left\|x^{\prime}\right\|_{\infty}$ and $P=\{x \in E: x(t) \geq$ $0, t \in[0,1]\}$ (this cone is not normal). Define $d: X \times X \rightarrow E$ by $d(x, y)=|x-y| \varphi$, where $\varphi:[0,1] \rightarrow \mathbb{R}$ such that $\varphi(t)=e^{t}$. Consider the mapping

$$
f(x)= \begin{cases}2 x^{2}-x, & 1 \leq x<2 \\ \frac{5}{2} x, & x \geq 2\end{cases}
$$

which implies that $f$ is onto in $X$. Taking $k=2, l=\frac{1}{4}, p=-\frac{1}{4}$, for $1 \leq x<2$, all the conditions of Corollary 2.2 are fulfilled. Indeed, since $0<\frac{1}{2} x+\frac{1}{2} y+\frac{3}{2}<2 x+2 y-1$, we have

$$
\begin{aligned}
d(f x, f y) & =\left|2 x^{2}-x-\left(2 y^{2}-y\right)\right| e^{t} \\
& =|(x-y)(2 x+2 y-1)| e^{t} \\
& \geq|x-y|\left(\frac{1}{2} x+\frac{1}{2} y+\frac{3}{2}\right) e^{t} \\
& =2|x-y| e^{t}+\frac{1}{2}|(x-y)(x+y-1)| e^{t} \\
& \geq 2|x-y| e^{t}+\frac{1}{4}\left|2 x-2 x^{2}\right| e^{t}-\frac{1}{4}\left|2 y-2 y^{2}\right| e^{t} .
\end{aligned}
$$

For $x \geq 2$, since $f(x)$ is increasing in $x$, we have

$$
d(f x, f y)=\left|\frac{5}{2} x-\frac{5}{2} y\right| e^{t} \geq 2|x-y| e^{t}+\frac{1}{4}\left|x-\frac{5}{2} x\right| e^{t}-\frac{1}{4}\left|y-\frac{5}{2} y\right| e^{t} .
$$


Therefore, we can apply Corollary 2.2 and conclude that $f$ has a (unique) fixed point 0 in $X$. Since $f$ is not continuous in $X$ and $l<1$, Theorem 2.6 in [9] is not applicable. Hence, our theorems have improved and generalized the main results in [9].

Example 2 Let $X=\{1,2,3\}$ and $d: X \times X \rightarrow \mathbb{R}^{2}$ be defined by $d(x, y)=(0,0)$ for $x=y$ and

$$
d(2,3)=d(3,2)=(0,0), \quad d(2,1)=d(1,2)=(1,1), \quad d(1,3)=d(3,1)=(1,1) .
$$

Then $(X, d)$ is a complete cone metric space. Further, define mappings $f, g: X \rightarrow X$ as follows:

$$
f(x)=\left\{\begin{array}{ll}
1, & x=1, \\
3, & x=2, \\
2, & x=3 ;
\end{array} \quad g(x)= \begin{cases}1, & x=1, \\
2, & x=2, \\
3, & x=3,\end{cases}\right.
$$

which implies that $f, g$ are onto in $X$. Note that

$$
d(f x, g y) \geq a_{1} d(x, y)+a_{2} d(x, f x)+a_{3} d(y, g y)+a_{4} d(x, g y)+a_{5} d(y, f x)
$$

for all $x, y \in X$ by taking $a_{1}=-\frac{1}{7}, a_{2}=-\frac{2}{7}, a_{3}=\frac{11}{7}, a_{4}=\frac{5}{7}, a_{5}=\frac{3}{7}$. Thus, all the conditions of Theorem 2.5 are fulfilled. Then $f$ and $g$ have a unique common fixed point 1 in $X$.

Remark 2.10 Obviously, in the above two examples, we obtain the (common) fixed point which essentially needs the structure of a cone metric and not an ordinary metric on $X$. Then the results in a metric space in [10] cannot be applied to these examples.

Competing interests

The authors declare that they have no competing interests.

Authors' contributions

All authors contributed equally and significantly in writing this paper. All authors read and approved the final manuscript.

\section{Author details}

${ }^{1}$ Department of Mathematics, Zhaotong University, Zhaotong, 657000, P.R. China. ${ }^{2}$ School of Mathematics and Statistics, Hubei Normal University, Huangshi, 435002, P.R. China.

\section{Acknowledgements}

The authors thank the editor and the referees for their valuable comments and suggestions which improve greatly the quality for this paper. The research was supported by the Foundation of Education Ministry, Hubei Province, China (No: D20102502).

Received: 28 December 2011 Accepted: 14 December 2012 Published: 7 January 2013

\section{References}

1. Huang, L-G, Zhang, X: Cone metric space and fixed point theorems of contractive mappings. J. Math. Anal. Appl. 332, 1468-1476 (2007)

2. Abbas, M, Jungck, G: Common fixed point results for noncommuting mappings without continuity in cone metric spaces. J. Math. Anal. Appl. 341, 416-420 (2008)

3. Abbas, M, Rhoades, BE: Fixed and periodic point results in cone metric spaces. Appl. Math. Lett. 22, $511-515$ (2009)

4. Radenovic, S: Common fixed points under contractive conditions in cone metric spaces. Comput. Math. Appl. 58, 1273-1278 (2009)

5. Altun, I, Damjanovic, B, Djoric, D: Fixed point and common fixed point theorems on ordered cone metric spaces. Appl. Math. Lett. 23, 310-316 (2010)

6. Rezapour, S, Hamlbarani, R: Some note on the paper "Cone metric spaces and fixed point theorems of contractive mappings". J. Math. Anal. Appl. 345, 719-724 (2008) 
7. Han, Y, Xu, S-Y: New common fixed point results for four maps on cone metric spaces. Appl. Math. 2, 1114-1118 (2011)

8. Bari, CD, Vetro, P: $\varphi$-pairs and common fixed points in cone metric spaces. Rend. Circ. Mat. Palermo 57, 279-285 (2008)

9. Aage, CT, Salunke, JN: Some fixed point theorems for expansion onto mappings on cone metric spaces. Acta Math. Sin. Engl. Ser. 27(6), 1101-1106 (2011)

10. Wang, S-Z, Li, B-Y, Gao, Z-M, Lseki, K: Some fixed points of expansion mappings. Math. Jpn. 29, 631-636 (1984)

11. Zhang, X: Common fixed point theorems of Lipschitz type mappings in cone metric spaces. Acta Math. Sin. 53(6), 1139-1148 (2010) (in Chinese)

doi:10.1186/1687-1812-2013-3

Cite this article as: Han and $\mathrm{Xu}$ : Some new theorems of expanding mappings without continuity in cone metric spaces. Fixed Point Theory and Applications 2013 2013:3.

Submit your manuscript to a SpringerOpen ${ }^{\circ}$ journal and benefit from:

- Convenient online submission

- Rigorous peer review

- Immediate publication on acceptance

- Open access: articles freely available online

- High visibility within the field

- Retaining the copyright to your article

Submit your next manuscript at $\gg$ springeropen.com 